Int. J. Morphol.,

35(4):1607-1613, 2017.

\title{
Biological Maturation Assessment Methods in Adolescent Soccer Players Considering Zinc Status
}

\author{
Métodos de Evaluación de la Maduración Biológica en Jugadores \\ Adolescentes de Fútbol Considerando el Estado de Zinc
}

\begin{abstract}
Astrogildo Oliveira-Junior ${ }^{1,2}$; Gustavo Casimiro-Lopes²; Carmem Marino Donangelo ${ }^{3,4}$
Josely Correa Koury ${ }^{5}$; Paulo Veras Farinatti ${ }^{2}$; Luís Miguel Massuça ${ }^{1,6}$ \& Isabel Fragoso ${ }^{1}$
\end{abstract}

OLIVEIRA-JUNIOR, A.; CASIMIRO-LOPES, G.; DONANGELO, C. M.; KOURY, J. C.; FARINATTI, P. V.; MASSUÇA, L. M. \& FRAGOSO, I. Biological maturation assessment methods in adolescent soccer players considering zinc status. Int. J. Morphol., 35(4):1607-1613, 2017.

SUMMARY: The purpose of this study was to compare different methods of maturity evaluation and their relation with performance-related physical and anthropometric variables in young soccer players, with different plasma zinc status. A total of 53 healthy male young soccer players (age: $13 \pm 1$ years; body mass: $48 \pm 10 \mathrm{~kg}$; stature: $160 \pm 10 \mathrm{~cm}$ ) participated in this study. Variables from physical fitness (stature, ST; fat-free mass, FFM; handgrip strength in the dominant hand, DHS), testosterone and zinc plasma concentration were measured. Biological maturity was evaluated by sexual maturity (development of: pubic hair, PH; genitals, GD; axillary hair; AH), bone maturity (TW3 method; BA), and testosterone plasma concentration methods. We observed that: (i) the frequency of hypozincemics and normozincemics children stratified by BA-CA, PH and GD were similar in each category; (ii) the BA allowed the identification of differences between the three categories, in at least two performance-related variables (FFM and DHS, p<0.0001); (iii) the AH method was able to discriminate only for DHS ( $\mathrm{p}<0.0001$ ); and (iv) the testosterone method was not able to identify differences between the four maturation categories with regard to ST, FFM, and DHS. Results suggested that Zinc deficiency did not influence the results obtained for the maturation categories defined by the different assessment methods. The assessment of biological maturation by BA seems to be the most effective for the stratification of performance-related and anthropometric variables in young soccer players. Nevertheless, the AH method should also be considered as a fair option to be used in field studies and practice.

KEY WORDS: Puberty; Testosterone; Sports; Biological maturation.

\section{INTRODUCTION}

In soccer, the chronological age is used to define the different categories of competition. It is not uncommon that subjects with different stages of maturation are included in the same categories, which may jeopardize long term training programs. The identification of biological maturation status is therefore relevant to design adequate physical training programs (Fragoso et al., 2004; Malina et al., 2004a; Figueiredo et al., 2010).

The determination of biological age is fundamental to estimate the potential performance of athletes, since some puberty characteristics can occur in distinct chronological ages. With such purpose, researchers commonly use maturity assessment methods based in secondary sexual characteristics, which may not reflect changes within narrow age ranges (Mortatti \& Arruda, 2007) in traits related to sports performance, for instance, stature, fat free mass, and strength (Fragoso et al.; Figueiredo et al., 2009). In other words, some physical and fitness characteristics are expected in children with a particular maturation status - methods to assess maturation should be able to discriminate for these characteristics, in order to avoid bias in children evaluation (Tanner et al., 2001).

\footnotetext{
${ }^{1}$ CIPER, Faculdade de Motricidade Humana, Universidade Técnica de Lisboa, Lisboa, Portugal.

${ }^{2}$ Instituto de Educação Física e Desportos, Universidade do Estado do Rio de Janeiro, Rio de Janeiro, Brasil.

${ }^{3}$ Instituto de Bioquímica, Universidade Federal do Rio de Janeiro, Rio de Janeiro, Brasil.

${ }^{4}$ Escuela de Nutrición, Universidad de la República, Uruguay.

${ }^{5}$ Instituto de Nutrição, Universidade do Estado do Rio de Janeiro, Rio de Janeiro , Brasil.

${ }^{6}$ Faculdade de Educação Física e Desporto, Universidade Lusófona de Humanidades e Tecnologias, Portugal.
} 
On the other hand, some potentially confounding factors may affect the maturity values obtained by different methods of classification. The zinc status is one of these factors, being an important health-related trace element (Micheletti et al., 2001; Hambidge et al., 2006; Bhowmik \& Kumar, 2010). During growth and biological maturation, zinc participates in bone, protein, lipid and carbohydrate metabolism (Wada, 2004). Additionally, it is involved in the synthesis of growth hormone, testosterone, insulin-like growth factor I (IGF-I), alkaline phosphatase, collagen, osteocalcin, insulin, vitamin D3 and leptin (Koury et al., 2007).

Temporary zinc deficiency it is not a rare event (Micheletti et al.). Increased levels of physical activity, stress, and poor dietary habits can negatively influence zinc homeostasis (Micheletti et al.). This condition can promote growth retardation, delayed bone development, fatigue, loss of body mass, and impaired development (sexual, motor and cognitive), which could preclude normal pubertal development and impair biological maturation (Salgueiro et al., 2002, 2004; Koury et al., 2005; Bhowmik \& Kumar).

In brief, it would be useful to clarify whether distinct techniques to determine maturation status can actually discriminate children with different biological age within initial soccer categories. Given the relevance of the zinc in organic functions and its possible influence on maturation assessment, it is also important to take into account how zinc status influences the maturity values obtained by these methods of classification. Thus, the aim of the present study was to compare different methods of maturity evaluation and their relation with performance-related physical and anthropometric variables in young soccer players, with different plasma zinc status.

\section{MATERIAL AND METHOD}

Participants. All participants were registered as athletes from an initial category (12-14 years-old) in the organizational structure of the Brazilian Soccer Federation. A total of 56 children participating of systematic soccer training in a traditional club of Rio de Janeiro, Brazil, initially enrolled in the study. From these, three did not participate of the whole protocol and dropped out. Therefore, 53 healthy young male subjects (age: $13 \pm 1$ years; body mass: $48 \pm 10 \mathrm{~kg}$; stature: $160 \pm 10 \mathrm{~cm}$; plasma zinc: $12.2 \pm 2.2 \mu \mathrm{mol} / \mathrm{L})$ participated in the study. They are compatible with the chronological age (NCHS percentiles 3 to 97) and sports modality. The overall sample had
$6.1 \pm 2.3$ years of previous experience with soccer practice and trained $5.0 \pm 1.8$ hours/week. None of the participants were using any vitamin or mineral supplementation. Information about the training volume (number of hours per week) was obtained through individual interviews. After detailed explanation of the study, all subjects' parents or legal guardians signed informed consent. The study was approved by the Ethical Committee of Pedro Ernesto University Hospital, Rio de Janeiro, Brazil, as recommended by the declaration of Helsinki.

Experimental design. Initialy, groups of six children attended the laboratory for blood and urine collection after an overnight fast. After eating a small meal, they performed hand x-ray, anthropometry and dynamometry measurements. Fat-free mass was quantified by dual-energy radiograph absorptiometry in a specialized clinic (Lunar Prodigy Advance - General EletricsTM, Chalfont St. Giles, United Kingdom). Considering the cut point $11.0 \mu \mathrm{mol} / \mathrm{L}$ for concentration of plasma zinc (Food and Nutrition Board, 2000), the athletes were divided in two groups: normozincemics $(n=37)$ and hypozincemics $(n=16)$. Due to their relation with soccer performance, stature (ST), fat-free mass (FFM), and strength were also assessed. These variables were used to analyze differences between groups and the ability of a given maturation technique to discriminate for characteristics related to performance.

Procedures. Body mass (BM) and stature (ST) were measured according International Society for the Advancement of Kinatropometry (ISAK) recommendations (Marfe11-Jones et al., 2006). Handgrip strength was assessed by dynamometry (model 78010, Lafayette $\AA$, USA), with scale in $\mathrm{kg}(0$ to $100 \mathrm{~kg})$ and accuracy of $1 \mathrm{~kg}$. The dominant hand higher value, after three attempts, was taken as final result (Innes, 1999).

Biological maturity was evaluated by three methods: (i) sexual maturity (SM); (ii) bone maturity; and (iii) testosterone plasma concentration.

The evaluation of SM, based on secondary sexual characteristics, considered the development of pubic hair (PH) and genitals (GD), according to five categories (1 to $5)$. The axillary hair $(\mathrm{AH})$ was evaluated according three categories (Tanner, 1962). PH and GD methods were performed by self evaluation (Cameron, 2002) to preserve subjects' privacy. Categories with small number of individuals $(n<4)$ were discarded. Three evaluations of sexual maturity were made in different moments throughout a period of six months, in order to verify the reproducibility of the self evaluations (Tanner, 1962). 
Bone maturity was evaluated by the estimation of bone age (BA), according to Tanner-Whitehouse 3 method (TW3) (Tanner et al.), based on x-ray measurements in 13 bones of the left hand. The $\mathrm{x}$-ray radiation dose was within the range of 3 to 5 mrem ( 0.003 to 0.007 rads), corresponding approximately to $5 \%$ of the allowed annual dosage (Machado \& Barbanti, 2007). The test-retest reproducibility of BA assessments was very high (within-observers: $\mathrm{r}=0.70$ and $\mathrm{p}<0.0001 ; \mathrm{t}=0.1033$ and $\mathrm{p}=0.91$; between-observers: $\mathrm{r}=0.96$ and $\mathrm{p}<0.0001 ; \mathrm{t}=0.4118$ and $\mathrm{p}=0.68$ ). The BA standard deviation allowed the division of athletes into three classes (sd -3 to $-1=11.1$ to 12.5 years; sd -1 to +1 $=12.6$ to 14.0 years; $\mathrm{sd}+1$ to $+3=14.1$ to 15.5 years). The BA compared to chronological age (CA) allowed the evaluation of 'maturational tempo' (rate of maturation progress). The difference between BA and CA (BA - CA) produces the following classifications: (i) later (LA) if $<$ than -1 ; (ii) synchronous (SY) if $>$ than -1 and $<$ than +1 ; and (iii) early (EA) if $>$ that +1 (Malina et al., 2004b).

Prior to blood collection, subjects were instructed to avoid physical activity for 16 hours. After an overnight fast (8h), a $10 \mathrm{~mL}$ blood sample was collected by antecubital vein puncture into heparinised (30U per tube) mineral-free tubes, being centrifuged at $1800 \mathrm{~g}$ for 10 min for separation of plasma, which was stored at $-200 \mathrm{C}$ to further analysis. Plasma testosterone was analyzed by radioimmunoassay, using a Coat-A-Count kit (Diagnostic Products Corporation, USA). The maturation classification for the testosterone plasma concentration followed the orientations of the manufacturer (Kühnel, 2000), stratifying the individuals in five maturational categories, i.e., Tanner stages: (i) $1.2-23 \mathrm{ng} / \mathrm{dL}$; (ii) $2.5-70 \mathrm{ng} / \mathrm{dL}$; (iii) $3.15-$ $280 \mathrm{ng} / \mathrm{dL}$; (iv) $4.105-545 \mathrm{ng} / \mathrm{dL}$; and (v) $5.265-800$ $\mathrm{ng} / \mathrm{dL}$. Plasma zinc was measured by inductively coupled plasma-optical emission spectrometry (Optima 4300 DV, PerkinElmer, USA PerkinElmer). Accuracy was validated by concordant results obtained from a reference material (whole blood, SeronormTM, lot 404109, NY AS, Pharma Diagnostics).
Statistical analysis. The normality and homogeneity of variances were ratified by univariate analysis. Therefore, differences among categories formed by each method were determined using one-way ANOVA following by Bonferroni post-hoc tests. The Student t-test was used to identify differences between normozincemics and hypozincemics, stratified by the maturation assessment methods. To analyze differences between the number of subjects in each age group, the chi-square test was applied. All calculations were made with the software GraphPad Prism version 5.00 for Windows (GraphPad Software, San Diego, CA, USA), and the significance level was fixed at $\mathrm{p} \leq 0.05$.

\section{RESULTS}

Participants characteristics are presented in Table I.

Performance-related variables analyzed in hypozincemic and normozincemic groups are presented in Figure 1. Except for zincemia, no significant differences were identified between the two groups in any of the variables. Since no difference related to zinc status was detected, data regarding to the potential value of maturation assessment techniques to discriminate for these variables were analyzed for the whole sample, regardless the zinc status.

The chi-square revealed that the frequency of hypozincemics and normozincemics children stratified by BA-CA was similar in each category (late, $31.3 \%$ and 31.6 $\%$; synchronous, $37.4 \%$ and $36.8 \%$; early, $31.3 \%$ and 31.6 $\%$; respectively, $\mathrm{p}=0.99)$. The same pattern was observed following GD ( $\mathrm{p}=0.99)$ and PP stratification $(\mathrm{p}=0.95)$.

The comparison between maturational categories defined by each assessment method is shown in Figure 2. The classification by testosterone concentration produced four categories, and the other methods only three. The BA allowed the identification of differences between the three

Table I. General characteristics of adolescent soccer players grouped by zinc nutritional status $(\mathrm{n}=53)$.

\begin{tabular}{lllll}
\hline & \multicolumn{2}{l}{ Hypozincemic $(\mathrm{n}=16)$} & \multicolumn{2}{c}{ Normozincemic $(\mathrm{n}=37)$} \\
& Mean & \pm SD & Mean & \pm SD \\
\hline Chronological age (years) & 13.3 & \pm 0.6 & 13.3 & \pm 0.7 \\
Bone age (years) & 13.0 & \pm 2.5 & 13.3 & \pm 1.8 \\
Body mass $(\mathrm{kg})$ & 46.3 & \pm 9.6 & 49.5 & \pm 10.2 \\
Stature $(\mathrm{cm})$ & 160.1 & \pm 10.8 & 160.4 & \pm 10.2 \\
Testosterone $(\mathrm{ng} / \mathrm{dl})$ & 329.7 & \pm 257.7 & 291.7 & \pm 205.9 \\
Plasma zinc $(\mu \mathrm{mol} / \mathrm{l})$ & 9.7 & \pm 1.3 & 13.2 & \pm 1.5 \\
Bone age - chronological age (years) & -0.29 & \pm 2.36 & -0.02 & \pm 1.45 \\
Axillary hair development & 1.8 & \pm 0.8 & 2.1 & \pm 0.8 \\
Genital development & 3.0 & \pm 0.8 & 2.8 & \pm 1.0 \\
Pubic hair development & 3.2 & \pm 1.2 & 3.4 & \pm 0.9 \\
\hline
\end{tabular}


categories, in at least two performance-related variables (FFM and DHS, $\mathrm{p}<0.0001$ ). The AH method was able to discriminate only for DHS $(\mathrm{p}<0.0001)$. Although providing four maturation categories, the testosterone method was not able to identify differences between these categories with regard to ST, FFM, and DHS.

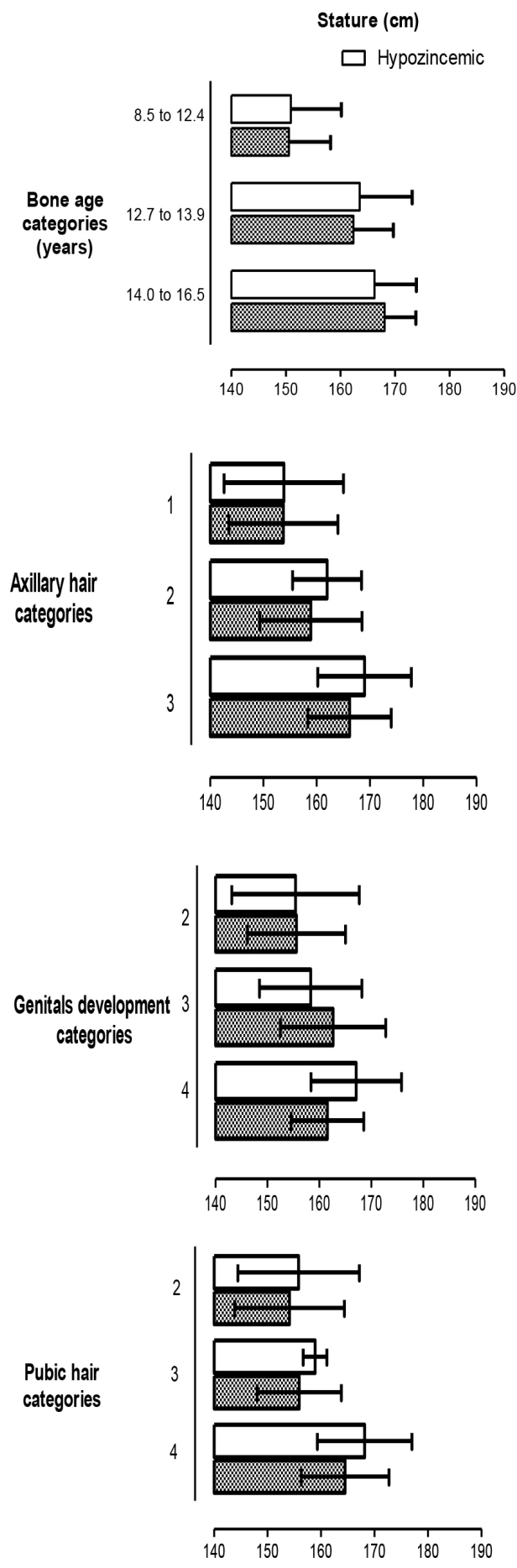

Fat-Free Mass (kg)
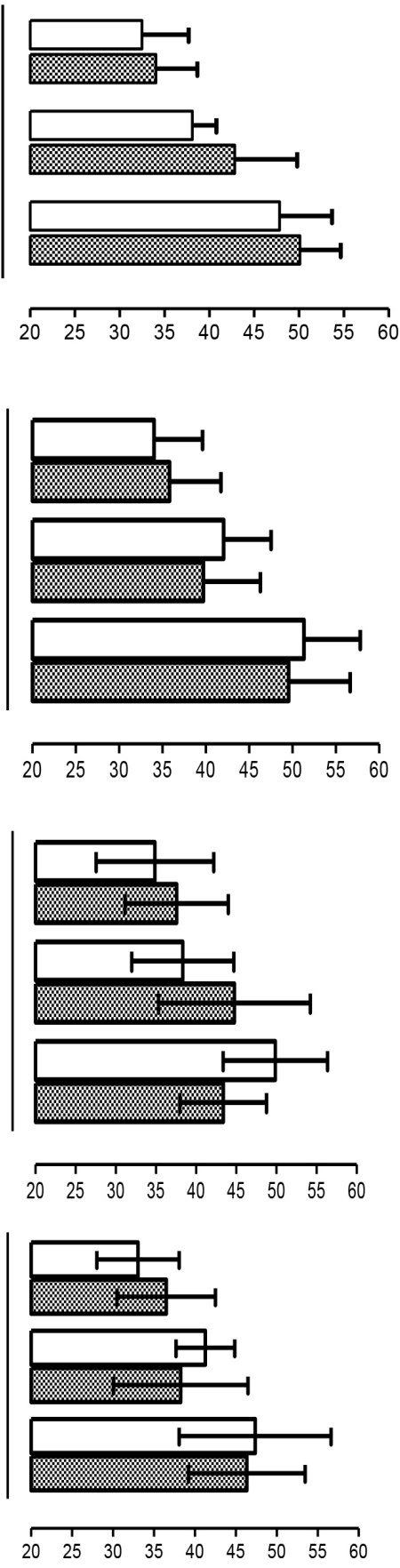

Dominant Hand Strength (kg)

Normozincemic
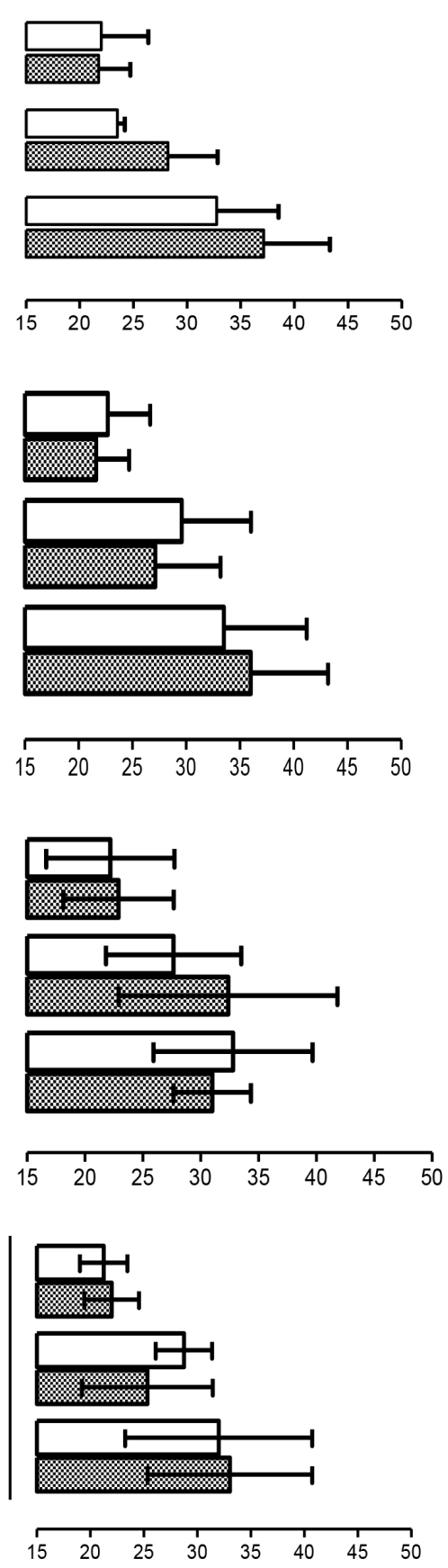

Fig. 1. Comparison of stature, fat-free mass and dominat hand strength between hypozincemic and normozincemic groups in each category of the different biological maturation assessment methods. 

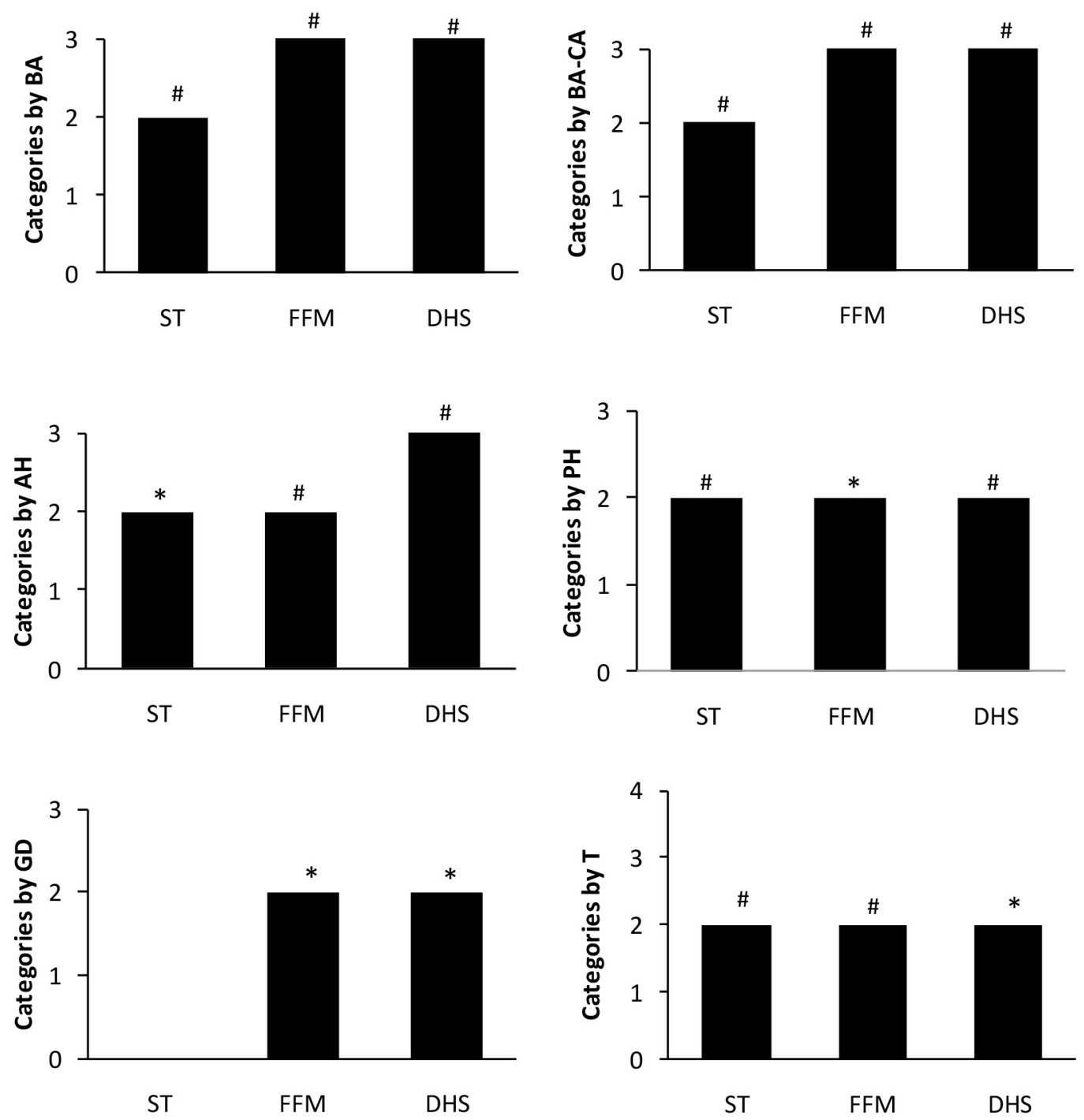

Fig. 2. Descriptive data about the number of categories with statistically significant differences in each maturation assessment method. *p<0.05; \#p<0.0001 BA, Bone Age; BA-CA, Bone Age - Chronological Age; T, Testosterone; AH, Axillary Hair; GD, Genital Development; PH, Pubic Hair; FFM, Fat-Free Mass; CA, Chronological Age; ST, Stature;DHS, Dominant Handgrip Strength.

\section{DISCUSSION}

Few studies have examined the influence of zinc in factors related to biological maturation, including bone metabolism and hormonal regulation (Sandstead et al., 1998). In our study, although plasma zinc was significant higher in normozincemic over hypozincemic group, no relationship whatsoever was observed between zinc and maturation status.

A possible explanation for this result is the possible effect of exercise practice on plasma zinc. Factors other than the diet also participate in zinc metabolism, like genetics, environment and disease (Wastney et al., 2000). It is well accepted that due to enzymatic utilization by superoxide dismutase or carbonic anydrase (Saliba et al., 2006) or by the muscle itself, the zinc concentration may decline as a consequence of low plasma concentration (Cordova \& Alvarez-Mon, 1995). In conditions of low zinc availability, the body spares endogenous zinc through intestine wall. Hence low zinc levels in hypozincemic athletes could be due to regular training and not diet deficit (Arikan et al., 2008). 
Although the maturation involves all organs and systems, it is not uncommon that a single indicator is adopted as representative of this process (Beunen et al., 2006). An efficient approach to assess the biological age should, among other characteristics, be able to identify discrete stages of the maturation (Beunen et al.). In this sense, classification methods as SM are able to identify satisfactorily the maturation status of individuals in a restricted group, at least at the peri-pubertal period.

Although some previous studies suggested that the maturation of children aged between 8-15 years-old could be correctly classified by SM, and that this would reflect differences variables in FFM and ST (Herman-Giddens et al., 2001), such possibility was not fully ratified by our results. Actually, significant differences in performance-related variables between the maturation categories were detected only for ST. As aforementioned, the discrimination potential of SM method is limited when children with close chronological age are evaluated, and this was indeed the case of the present study. Future research is warrant to investigate whether SM may be applied in the sports context.

Previous research indicated that BA would be strongly associated with handgrip strength in adolescent soccer players (Fragoso et al.). In our study, the classification using BA allowed the identification of significant differences between maturation categories with regard to all performance-related variables, including DHS. This result agrees with other studies suggesting that BA would be efficient to discriminate distinct maturation stages (Fragoso et al.; Beunen et al.). Additionally, the 'maturational tempo' categories estimated from BA-CA (early, synchronous, and delayed) agreed with the directly assessed testosterone levels. Early mature boys $(\mathrm{BA}-\mathrm{CA} \geq 1)$ presented lower testosterone values compared to those with late maturation (BA-CA $\leq-1)$ $(\mathrm{p}=0.0017)$, but were not different than synchronous $(\mathrm{p}>0.05)$. Therefore, the BA technique seemed to be quite well related to the expected behavior of both performance-related and physiological variables in the different maturation stages.

The AH method is similar to SM in which concerns the application principle, since it is a secondary sexual characteristic. In comparison with SM, the AH can only be applied in later stages of maturation, since axillary hair develops after pubic hair and in the presence of higher testosterone concentration. Interestingly, after $\mathrm{BA}, \mathrm{AH}$ and $\mathrm{PH}$ were the best methods to discriminate for the performance-related variables, being able to identify differences across the two more advanced maturation categories for FFM and DHS. Since the application of AH is evidently easier than BA and $\mathrm{PH}$, this could be a quite practical option to the practitioner, at least for children at the end of puberty.
Anthropometric parameters seem to be separately associated with maturational status and serum testosterone concentrations. Additionally, testosterone normally increases with age in boys (Ramos et al., 1998), however in our study we did not find any significant differences between categories originated from testosterone levels with none of the maturation methods evaluated.

Some limitations of the present study must be acknowledged. Firstly, the results refer to young males within a narrow age range. Future research should investigate the applicability of different maturation assessment techniques in other age categories. Aspects such ethnicity and social class were not considered in the study. These factors should be controlled, given their influence on potential confounding factors as diet pattern, body composition, and strength. Studies with females should also be encouraged to a better understanding of the potential application of distinct maturation assessment techniques in the soccer context.

In accordance, it seems that: (i) zinc deficiency did not influence the results obtained for the maturation categories defined by the different assessment methods; and (ii) the assessment of biological maturation by BA was the most effective for the stratification of performance-related and anthropometric variables in young soccer players. However, the AH method also seems to be efficient. Taken that in consideration, and given its simplicity and low cost, the $\mathrm{AH}$ method should be considered as a fair option to be used in field studies and practice.

ACKNOWLEDGEMENTS. This study was partially supported by FAPERJ and CNPq.

OLIVEIRA-JUNIOR, A.; CASIMIRO-LOPES, G.; DONANGELO, C. M.; KOURY, J. C.; FARINATTI, P. V.; MASSUÇA, L. M. \& FRAGOSO, I. Métodos de evaluación de la maduración biológica en jugadores adolescentes de fútbol considerando el estado de zinc. Int. J. Morphol., 35(4):1607-1613, 2017.

RESUMEN: El objetivo de este estudio fue comparar diferentes métodos de evaluación de madurez y su relación con variables físicas y antropométricas relacionadas con el desempeño en jóvenes jugadores de fútbol, con diferentes niveles plasmáticos de zinc. Participaron en este estudio 53 jugadores de fútbol jóvenes sanos (edad: $13 \pm 1$ años, masa corporal: $48 \pm 10 \mathrm{~kg}$, estatura: $160 \pm$ $10 \mathrm{~cm}$ ). Se midieron las variables de la aptitud física (estatura, ST, masa libre de grasa, FFM, fuerza de agarre en la mano dominante, DHS), testosterona y concentración plasmática de zinc. Se evaluaron la madurez sexual (desarrollo de vello púbico, $\mathrm{PH}$, genitales, DG, cabello axilar, AH), madurez ósea (método TW3, BA) y concentración plasmática de testosterona. Se observó que: (i) la frecuencia de los niños hipoxincémicos y normozincémicos estratificados por BA-CA, PH y GD fueron similares en cada categoría; (ii) el BA 
permitió la identificación de diferencias entre las tres categorías, en al menos dos variables relacionadas con el desempeño (FFM y DHS, p <0,0001); (iii) el método AH fue capaz de discriminar sólo para DHS ( $\mathrm{p}<0,0001$ ); y (iv) el método de testosterona no fue capaz de identificar diferencias entre las cuatro categorías de maduración con respecto a ST, FFM y DHS. Los resultados sugirieron que la deficiencia de zinc no influyó en los resultados obtenidos para las categorías de maduración definidas por los diferentes métodos de evaluación. La evaluación de la maduración biológica por BA parece ser la más efectiva para la estratificación de variables de rendimiento y antropométricas en jóvenes jugadores de fútbol. Sin embargo, el método AH también debe ser considerado como una opción justa para ser utilizado en estudios de campo y práctica.

PALABRAS CLAVE: Pubertad; Testosterona; Deportes; Maduración biológica

\section{REFERENCES}

Arikan, S.; Akkus, H.; Halifeoglu, I. \& Baltaci, A. K. Comparison of plasma leptin and zinc levels in elite athletes and sedentary people. Cell Biochem. Funct., 26(6):655-8, 2008.

Beunen, G. P.; Rogol,A. D. \& Malina, R. M. Indicators of biological maturation and secular changes in biological maturation. Food Nutr. Bull., 27(4 Suppl. Growth Standard):S244-56, 2006

Bhowmik, D. \& Kumar, K.P. S. A potential medicinal importance of zinc in human health and chronic disease. Int.J. Pharm. Biomed. Sci., 1(1):5-11, 2010.

Cameron, N. Assessment of Maturation Human Growth and Development. San Diego, Academic Press, 2002. pp.363-82.

Cordova, A. \& Alvarez-Mon, M. Behaviour of zinc in physical exercise: a special reference to immunity and fatigue. Neurosci. Biobehav. Rev., 19(3):439-45, 1995

Figueiredo, A. J.; Coelho e Silva, M. J. \& Malina, R. M. Predictors of functional capacity and skill in youth soccer players. Scand. J. Med.Sci. Sports, 23(3):446-54, 2010

Figueiredo, A. J.; Gonçalves, C. E.; Coelho E Silva, M. J. \& Malina, R. M. Youth soccer players, 11-14 years: maturity, size, function, skill and goal orientation. Ann. Hum. Biol., 36(1):60-73, 2009.

Food and Nutrition Board, I. M. Dietary Reference Intakes for Vitamin A, Vitamin K, Arsenic, Boron, Chromium, Copper, Iodine, Iron, Manganese, Molybdenum, Nickel, Silicon, Vanadium, and Zinc. Washington D. C., National Academies Press, Institute of Medicine, 2000

Fragoso, I.; Vieira, F.; Castro, L.C.; Oliveira Junior,A.; Capela, C. \& Oliveira, N Maturation and Strength of Adolescent Soccer Players. Children and Youth in Organized Sports. Coimbra, Coimbra University Press, 2004. pp.199-208

Hambidge, K. M.; Krebs, N. F.; Westcott, J. E. \& Miller, L. V. Changes in zinc absorption during development. J. Pediatr., 149(5 Suppl.):S64-8, 2006.

Herman-Giddens, M. E.; Wang, L. \& Koch, G. Secondary sexual characteristics in boys: estimates from the national health and nutrition examination survey III, 1988-1994. Arch. Pediatr. Adolesc. Med., 155(9):1022-8, 2001.

Innes, E. Handgrip strength testing: A review of the literature. Aust. Occup. Ther. J., 46(3):120-40, 1999 .

Koury, J. C.; de Oliveira, C. F.; Portella, E. S.; Oliveira, A. V. Jr. \& Donangelo, C. M. Effect of the period of resting in elite judo athletes: hematological indices and copper/ zinc-dependent antioxidant capacity. Biol.Trace Elem. Res., 107(3):201-11, 2005

Koury, J. C.; de Oliveira, K. de J.; Lopes, G. C.; de Oliveira, A. V. Jr.; Portella, E. S.; de Moura, E. G. \& Donangelo, C. M. Plasma zinc, copper, leptin, and body composition are associated in elite female judo athletes. Biol. Trace Elem. Res., 115(1):23-30, 2007.

Kühnel, W. Immulite and Immulite 2000: Reference Range Compendium. Los Angeles, Diagnostic Products Corporation, 2000. pp.75.

Machado, D. R. L. \& Barbanti, V. J. Maturação esquelética e crescimento em crianças e adolescentes. Rev. Bras. Cineantropom. Desempenho Hum. 9(1):12-20, 2007.

Malina, R. M.; Bouchard, C. \& Bar-Or, O. Biological Maturation: Concepts and Assessment Growth, Maturation and Physical Activity. 2nd ed. Champaign, Human Kinetics, 2004a. pp.277-306.

Malina, R. M.; Eisenmann, J. C.; Cumming, S. P.; Ribeiro, B. \& Aroso, J. Maturity-associated variation in the growth and functional capacities of youth football (soccer) players 13-15 years. Eur. J. Appl. Physiol., 91(56):555-62, 2004b

Marfell-Jones, M.; Olds, T.; Stewart,A. \& Carter, J. E. L. International Standards for Anthropometric Assessment. Potchefstroom, The International Society for the Advancement of Kinanthropometry, 2006.

Micheletti, A.; Rossi, R. \& Rufini, S. Zinc status in athletes: relation to diet and exercise. Sports Med., 31(8):577-82, 2001.

Mortatti, A. L. \& Arruda, M. Análise do efeito do treinamento e da maturação sexual sobre o somatotipo de jovens futebolistas. Rev. Bras. Cineantropom. Desempenho Hum., 9(1):84-91, 2007.

Ramos, E.; Frontera, W. R.; Llopart, A. \& Feliciano, D. Muscle strength and hormonal levels in adolescents: gender related differences. Int. J. Sports Med., 19(8):526-31, 1998.

Salgueiro, M. J.; Weill, R.; Zubillaga, M.; Lysionek, A.; Caro, R.; Goldman, C.; Barrado, D.; Sarrasague, M. M.; Ridolfi, A. \& Boccio, J.Zinc deficiency and growth: current concepts in relationship to two important points: intellectual and sexual development. Biol. Trace Elem. Res., 99(1-3):49-69, 2004.

Salgueiro, M. J.; Zubillaga, M. B.; Lysionek, A. E.; Caro, R. A.; Weill, R. \& Boccio, J. R. The role of zinc in the growth and development of children. Nutrition, 18(6):510-9, 2002.

Saliba, L. F., Tramonte, V. L. C. G. \& Faccin, G. L. Plasma and erythrocyte zinc in Brazilian professional female volleyball players. Rev. Nutr., 19(5):58190, 2006.

Sandstead, H. H.; Penland, J. G.; Alcock, N. W.; Dayal, H. H.; Chen, X. C.; Li, J. S.; Zhao, F. \& Yang, J. J. Effects of repletion with zinc and other micronutrients on neuropsychologic performance and growth of Chinese children. Am. J. Clin. Nutr., 68(2 Suppl.):470S-5S, 1998.

Tanner, J. M. Growth at Adolescence. 2nd ed. Oxford, Blackwell Scientific Publications, 1962.

Tanner, J. M.; Healy, M. J. R.; Goldstein, H. \& Cameron, N. Assessment of Skeletal Maturity and Prediction of Adult Height (Tw3 Method). $3^{\text {rd }}$ ed. London, W. B. Saunders, 2001.

Wada, O. What are trace elements? Their deficiency and excess states. Jpn. Med.Assoc. J., 47(8):351-8, 2004.

Wastney, M. E.; House, W. A.; Barnes, R. M. \& Subramanian, K. N. Kinetics of zinc metabolism: variation with diet, genetics and disease. J.Nutr., $130(5 \mathrm{~S}$ Suppl.):1355S-9S, 2000.

\section{Corresponding author: \\ Luís Miguel Massuça \\ Lusófona University \\ Faculty of Physical Educationa and Sport \\ Campo Grande, 376, room H.1.2. \\ 1749-024 Lisbon \\ PORTUGAL}

E-mail: luis.massuca@gmail.com

Received: 05-07-2017

Accepted: 06-09-2017 